\title{
A GESTÃO DEMOCRÁTICA LOCAL: DESAFIOS E PERSPECTIVAS DOS INSTRUMENTOS DELIBERATIVOS NO BRASIL
}

\section{LOCAL DEMOCRATIC MANAGEMENT: CHALLENGES AND PROSPECTS OF DELIBERATIVE INSTRUMENTS IN BRAZIL}

\section{Denise Bittencourt Friedrich ${ }^{1}$ Cynthia Gruendling Juruena ${ }^{2}$}

\section{Resumo}

O presente artigo visou a abordar a democracia deliberativa e a sua imprescindibilidade na esfera local, a fim de que a partir desse lócus possa haver uma ampliação no diálogo entre Estado e sociedade, para que, assim, os cidadãos tenham maior participação nos assuntos públicos. Dessa forma, tratou-se primeiramente das matrizes teóricas da democracia deliberativa, conferindo um enfoque ao referencial de Jürgen Habermas. Logo após, enfatizouse a importância do espaço local na interlocução entre Estado e sociedade, destacando a proximidade dos cidadãos com o ente local. Nesse sentido, a partir da esfera local, realizou-se uma análise dos instrumentos de deliberação pública existentes, questionando se os mesmos são suficientes para possibilitar essa ampliação no diálogo do Estado e dos cidadãos e se correspondem aos preceitos teóricos de democracia deliberativa de Habermas. Os resultados preliminares mostram que há a necessidade de uma formatação nos instrumentos participativos e deliberativos para que de fato possibilitem o processo democrático deliberativo, visto que os instrumentos disponíveis apresentam entraves que dificultam a participação dos cidadãos nas deliberações. A metodologia de pesquisa utilizada na presente pesquisa foi o método hipotético-dedutivo, do qual partiu-se da hipótese de que os espaços deliberativos são insuficientes para uma aproximação dos cidadãos e do poder público.

Palavras-chave: democracia deliberativa; esfera local; Estado; sociedade.

\footnotetext{
${ }^{1}$ Professora da Pós-graduação em Direito e da Graduação da Universidade de Santa Cruz do Sul. Doutora em Direito pela Universidade de Santa Cruz do Sul (UNISC). E-mail: d-friedrich@hotmail.com

2 Doutoranda em Direito pela Pontifícia Universidade Católica do Paraná. E-mail: cjuruena@gmail.com
} 


\section{Abstract}

The present article aimed to approach the deliberative democracy and its indispensability at the local level, so that from this locus there can be an expansion in the dialogue between State and society, so that citizens have greater participation in public affairs. In this way, the theoretical matrices of deliberative democracy were first treated, giving an approach to the reference of Jürgen Habermas. Afterwards, it was emphasized the importance of local space in the interlocution between State and society, emphasizing the proximity of the citizens with the local entity. In this sense, from the local sphere, an analysis of the existing instruments of public deliberation was carried out, and whether they are sufficient to allow this expansion in the dialogue of the State and the citizens and correspond to Habermas's theoretical precepts of deliberative democracy. The preliminary results were that there is a need for formatting in the participatory and deliberative instruments to actually enable the deliberative democratic process, since the available instruments present obstacles that hinder citizen participation in the deliberations. The research methodology used in the present research was the hypothetical-deductive method, where we started from the hypothesis that deliberative spaces are insufficient for an approximation of citizens and public power.

Keywords: deliberative democracy; local sphere; society; State.

\section{CONSIDERAÇÕES INICIAIS}

O presente ensaio tem por escopo o de verificar a imprescindibilidade da democracia deliberativa para o fortalecimento da esfera local e para que haja maior interlocução entre o Estado e a sociedade.

Dessa forma, analisar-se-á as matrizes teóricas da democracia deliberativa, não sendo possível, entretanto, o esgotamento desse modelo. Será verificado certos aspectos desse processo de deliberação política democrática a partir de Jürgen Habermas e de alguns estudiosos deste referencial, onde a sociedade exerce importante papel.

Para mais, a partir do âmbito local, será referenciado que é possível que nesse espaço haja maior interlocução entre o Estado e a sociedade. Assim, tratar-se-á de que forma a esfera local impulsiona essa ampliação no diálogo dos cidadãos com o ente estatal.

Ao final, será realizado um estudo dos instrumentos existentes para que ocorra a deliberação pública na esfera local, verificando se os mesmos se demonstram suficientes para a 
ampliação e o fortalecimento dos espaços democráticos para os cidadãos em sede de decisões públicas.

A problemática que se coloca aqui é a de verificar se os instrumentos de democracia deliberativa que se dispõe no cenário brasileiro, especificamente em nível local, conseguem alcançar os cidadãos e fazer com que haja essa maior participação pública, analisando-se, neste caso, a partir do âmbito local.

A metodologia empregada na presente pesquisa foi o método hipotético-dedutivo, onde se acredita que é imprescindível a democracia deliberativa para a interlocução entre Estado e sociedade. Pretende-se constatar que deve haver mais momentos de deliberação pública na esfera local. O método de procedimento utilizado neste trabalho consistirá em uma abordagem bibliográfica e documental para investigar o tema com sua fundamentação teórica, justificando seus limites e contribuições

\section{MATRIZES TEÓRICAS DA DEMOCRACIA DELIBERATIVA}

A democracia deliberativa se consubstancia em um processo de deliberação política democrática, onde a participação da sociedade civil é incorporada à regulação da vida coletiva. Um dos principais referenciais deste modelo é Jürgen Habermas ${ }^{3}$, o qual aqui será adotado.

A democracia deliberativa pode ser considerada como uma forma de evolução da democracia participativa, sendo que a democracia deliberativa está correlacionada com a alteração das formas de participação da sociedade civil. Isso significa dizer que a democracia deliberativa é uma forma de exercício da democracia participativa, na qual se entende que a participação pública vai além do processo eleitoral, havendo uma maior interlocução dos indivíduos com a esfera pública (LEAL, 2011, p. 13-15).

Dessa forma, pode-se extrair que todo processo deliberativo democrático se afigura e depende de práticas participativas. No entanto, nem toda democracia participativa implicará em uma deliberação. O sufrágio universal é uma forma de participação política, mas não se

\footnotetext{
${ }^{3}$ Há outros expoentes na democracia deliberativa, como Joshua Cohen (ver: COHEN, Joshua. Deliberation and Democratic Legitimacy. In: MATRAVERS, Derek; PIKE, Jon (Eds.). Debates in contemporary political philosophy: an anthology. Estados Unidos da América e Canadá: Routledge, 2003, p. 342-360) e John Rawls (ver: RAWLS, John. Uma teoria da justiça. São Paulo: Martins Fontes, 1997). No entanto, não é possível esgotar aqui as vertentes da democracia deliberativa, tendo se elegido o autor Jürgen Habermas como matriz teórica para expor a importância de espaços deliberativos na sociedade.
} 
configura em democracia deliberativa. Já o orçamento participativo é um exemplo de prática do modelo deliberativo.

Assim, a democracia na concepção deliberativa é mais do que simplesmente exercer o seu voto, isto é, vai além de registrar as suas preferências. A partir do diálogo dos cidadãos, a democracia deliberativa busca que eles alcancem as melhores preferências que satisfaçam o interesse público (CUNNINGHAM, 2009, p. 194-195).

Importa ressaltar que tanto a democracia participativa quanto a democracia deliberativa encontram-se no mesmo campo teórico, isto é, se ocupam da problemática de como instituir e conferir maior efetividade à participação pública e à abertura dos processos de decisão pública. Nesta senda, "[...] o conceito deliberativo remete a complexos conjuntos teóricos, com conotações fortemente normativas, enquanto que a participação implica aspectos sobretudos aplicativos" (LEAL, 2011, p. 14-15).

O processo democrático será legítimo se permitir e encorajar a deliberação pública em questões específicas. Além disso, importa ressaltar que os cidadãos devem ser aptos para que, de forma livre e igualitária, alcancem preferências a partir do processo deliberativo e exercitem as habilidades necessárias para a participação nos fóruns (CUNNINGHAM, 2009, p. 120-121).

Com isso, tem-se que: "[...] a concepção de uma democracia deliberativa requer a possibilidade de que os cidadãos (indivíduos ou grupos) - a partir de suas respectivas orientações para um ponto comum - convirjam para um espaço público de discussão (um fórum) no qual uma decisão legítima, fruto de um debate público, será tomada" (MONTEIRO, 2006, p. 197).

Para a construção de processo democrático deliberativo de Habermas, o autor perpassa as concepções liberal e republicana, pois a democracia deliberativa irá surgir como uma outra via a esses modelos. Inclusive, as crises pós-68 fizeram com que houvesse uma desilusão com o modelo de democracia liberal, tendo-se a necessidade de um modelo democrático que incorporasse o poder local, democracia nos locais de trabalho, deliberação entre os cidadãos, dentre outros (MONTEIRO, 2006, p. 197).

Habermas (2007, p. 269-270) aponta para a diferença existente na compreensão do papel que cabe ao processo democrático, onde, segundo a concepção liberal, a tarefa é que o Estado se volte para o interesse da sociedade. Conforme a concepção republicana, a política é constitutiva do processo de coletivização social como um todo, isto é, os cidadãos que irão dar prosseguimento às relações já estabelecidas de reconhecimento mútuo. 
O conceito de cidadão, para a concepção liberal, se dará de acordo com os direitos individuais que ele dispõe em face do Estado e dos demais cidadãos. Já para a concepção republicana, não se determina o status de cidadão conforme as liberdades negativas, e sim, tem-se que os direitos de cidadania, direitos de participação e comunicação política são, em primeira linha, direitos positivos (HABERMAS, 2007, p. 271-272).

Para a concepção liberal, os direitos são entendidos a partir de quais são cabíveis aos indivíduos em cada caso concreto, enquanto que no projeto republicano os direitos são vistos a partir da integridade do indivíduo e de suas liberdades subjetivas bem como, em peso igual, da integridade da comunidade. Isto pois, é a partir da comunidade que o sujeito pode se reconhecer como membro e como indivíduo (HABERMAS, 2007, p. 272-273).

É a partir do delineamento do que seria política, direito, democracia, e outros conceitos para as concepções liberal e republicana, que Habermas delineia o modelo deliberativo, que através da comunicação que o processo político alcançará resultados racionais. Nesse sentido, a deliberação traçada pelo autor trabalha a diversidade das formas comunicativas, não apenas por um auto-entedimento mútuo de caráter ético, "[...] mas também pela busca de equilíbrio entre interesses divergentes e do estabelecimento de acordos, da checagem da coerência jurídica, de uma escolha de instrumento racional e voltada a um fim específico e por meio, enfim, de uma fundamentação moral" (HABERMAS, 2007, p. 277).

Nesta senda, além de haver a necessidade de uma participação dos cidadãos de forma livre e igualitária, deve-se haver um instrumento racional para guiar o processo democrático deliberativo. Habermas (2007, p. 278), então, desenvolve a teoria do discurso, que seria o procedimento para o aconselhamento e a tomada de decisões. Este procedimento "[...] cria uma coesão interna entre negociações, discursos de auto-entendimento e discursos sobre a justiça, além de fundamentar a suposição de que sob tais condições se almejam resultados ora racionais, ora justos e honestos".

A teoria do discurso (também conhecida como teoria da ação comunicativa) consubstancia-se na premissa de que as relações sociais modernas são amparadas na relação de comunicação e linguagem, sendo dissonante que se aceite relações monológicas e autoritárias. Nesta senda, a tese da Teoria da Ação Comunicativa (TAC) proposta por Jürgen Habermas entende que a comunicação dialógica é o ponto de partida da relação intersubjetiva, pressupondo-se que todos são orientados pela mútua compreensão (HABERMAS, 2003). 
Habermas entende a linguagem como um traço de distinção do ser humano, pois atribui à linguagem a capacidade de tornar-se um ser social e cultural. ${ }^{4}$ Neste sentido, é a partir da linguagem e da argumentação racional que o autor defende que ocorrerá a tomada de decisões da coletividade, diante uma relação intersubjetiva e plural (HABERMAS, 2000, p. 0810).

Neste contexto, o processo democrático deliberativo proposto por Habermas (2007) é entendido como um mecanismo de análise dos sistemas sociais e processos constitutivos da decisão, devendo ocorrer um compromisso comunicativo de entendimento e deliberação entre os cidadãos, para que, dessa forma, gere consensos legítimos. No entanto, para que haja a razoabilidade de uma concepção política, não se pode esperar dos cidadãos nenhum consenso se estes não estiverem dispostos a adotar um ponto de vista moral independente das distintas doutrinas compreensivas que cada um assume para si (HABERMAS, 1998).

Por isso que a teoria da ação comunicativa (ou teoria do discurso) encontra-se intimamente interligada com a democracia deliberativa, pois depreende que o direito só pode ser compreendido a partir da liberdade de compreensão de cada indivíduo acerca das ações do Estado (MOREIRA, 2002). Nesta senda, é a partir da comunicação e de argumentação racional que haverá uma relação dialógica entre a sociedade e o Estado.

"Daí que, de forma coerente, para Habermas, a maturidade da democracia mede-se pelo nível da comunicação pública comunitária, tomando-a aqui como a constituição política na qual a sociedade obtém a consciência mais pura de si mesma" (LEAL, 2011, p. 35). Neste viés, a sociedade será mais democrática se tiver um papel decisivo na reflexão dos assuntos públicos, devendo o poder público, dessa forma, fornecer e estimular espaços para que os cidadãos se apropriem de questões de interesse público.

Expostas as matrizes teóricas da democracia deliberativa e visto a sua importância para a interlocução entre os cidadãos e o Estado, será trabalhada a esfera local como o espaço mais propicio para que ocorra essa intercomunicação.

\footnotetext{
${ }^{4}$ Gadamer traz que a linguagem só tem o seu ser próprio no diálogo, quando há o processo de entendimento. Todas as comunidades humanas são formas de comunidade linguística, e é através da linguagem que pode se chegar em um acordo ou consenso dentro de uma comunidade humana. In: OLIVEIRA, Manfredo Araújo. Reviravolta lingüístico-pragmática na filosofia contemporânea. São Paulo: Loyola, 1996, p. 236-239.
} 


\section{A IMPORTÂNCIA DA ESFERA LOCAL NA INTERLOCUÇÃO ENTRE ESTADO E SOCIEDADE}

Analisada a matriz teórica do processo democrático deliberativo, de suas especificidades e de sua importância para que os cidadãos tomem parte em decisões públicas, verificar-se-á a importância da esfera local nessa interlocução entre Estado e sociedade, a qual será ampliada mediante a inserção de instrumentos deliberativos.

“Na América Latina, os processos de democratização política e de descentralização do Estado revalorizaram, ao longo da década passada, o papel das cidades e dos governos locais" (CASTELLS; BORJA, 1996, p. 154).

A Constituição de 1988 teve por escopo o de reformular o federalismo brasileiro (visto que a Constituição de 1988 é posterior ao regime militar, que não implementou o federalismo cooperativo), buscando avançar na direção de um federalismo centrífugo. Este pacto federativo procura que haja uma descentralização e estabelece, além da União, Estados e Distrito Federal, pela primeira vez a esfera municipal (MAGALHÃES, 2000, p. 19).

Dessa forma, com a promulgação da Constituição Federal de 1988, em que se consagra a adoção do federalismo e a inclusão dos municípios como ente federado, emerge a discussão do papel do município, devido à ampliação de sua capacidade de atuação. Assim, inicia-se maior debate sobre a autonomia municipal e sobre a esfera local.

Primeiramente, se faz mister delinear o que se entende por esfera/espaço local. Este lócus pode ser o município ou o bairro, onde a partir desse espaço o cidadão pode recuperar a dimensão de cidadania. O poder local seria a criação, em um município, de uma capacidade de autotransformação, tanto econômica quanto social (DOWBOR, 2008b, p. 03-09).

“Em particular, ao se deslocar boa parte das iniciativas do desenvolvimento para o nível local, aproxima-se a decisão do espaço onde o cidadão pode efetivamente participar" (DOWBOR, 2008a, p. 85). Nesse sentido, o espaço local assume significativa importância para que o cidadão se integre dos assuntos públicos.

A autonomia local, conceito utilizado pela Carta Europeia, se refere ao direito e à capacidade efetiva que as autarquias locais possuem de gerir uma parte dos assuntos públicos que estão sob sua responsabilidade (OLIVEIRA, 2012, p. 68-69). Já o poder local decorre da valorização do espaço local, e isso é um processo que demanda tempo. O poder local implica em alterações no sistema de organização das informações públicas, na capacidade 
administrativa e se constitui em um amplo trabalho de formação que envolve tanto a comunidade quanto a administração pública local (DOWBOR, 2008b, p. 20-26).

Ainda que estejamos na era da globalização ${ }^{5}$, deve-se ter presente que nem tudo é global. As ruas de nossa cidade, o patrimônio histórico, as escolas, dentre outros, dependem de iniciativas locais (DOWBOR, 2008b, p. 20-26). Nesse sentido, há decisões públicas que devem ser tomadas próximas ao cidadão, e muitas vezes chamando-o para ocupar o papel de ator social.

A cidade é, historicamente e atualmente, urbs, civitas e polis. A urbs, atualmente, é difícil de delimitar, pois há realidades diferentes, como cidade histórica, área metropolitana, aglomeração urbana, dentre outros. Assim, a partir dessa diversidade de elementos territoriais, acaba por refletir no exercício da cidadania, pela multiplicidade de territórios e identidades. A civitas é tida como o local que produz a cidadania e âmbito de exercício desta. A civitas não é uma unidade homogênea, visto que a sociedade urbana é heterogênea. O ideal de sociedade urbana entendida como civitas é de uma coletividade baseada na igualdade, convivência e tolerância; heterogênea, mas com valores básicos (BORJA; MUXí, 2003, p. 63-65).

É também a polis o lugar da política, da política de proximidade, do autogoverno e da auto representação da sociedade. "A pesar de la existencia de los Estados y de la "globalización política", la ciudad vale como lugar político, pero también como representación de la identidad colectiva de la sociedad urbana, por ello se reivindica el gobierno de proximidad, la concertación entre instituciones y actores sociales para llevar a cabo proyectos colectivos" (BORJA; MUXí, 2003, p. 65).

Será no espaço municipal que o cidadão, o ator social, deixará o plano da abstração e passará a ser entendido conforme as especificidades e necessidades concretas daquela esfera a que ele pertence. É a partir do espaço local que será possível a atuação desses atores para a formação de decisões públicas, decorrentes de uma apropriação desse espaço pela sociedade. ${ }^{6}$

Neste sentido, Baracho (1996, p. 19) assevera que "o melhor clima das relações entre cidadãos e autoridades deve iniciar-se nos municípios, tendo em vista o conhecimento

\footnotetext{
${ }^{5}$ Quanto à globalização, destaca-se que "[...] a consolidação de um novo paradigma de cidadania não prescinde do modelo de Estado Nacional, tampouco nega o processo de globalização, mas, sim, constituise em modelo de convivência, coexistência de diferentes esferas de poder" In: HERMANY, Ricardo. (Re)Discutindo o espaço local: uma abordagem a partir do direito social de Gurvitch. Santa Cruz do Sul: Edunisc, 2007, p. 252.

${ }^{6}$ A partir da nova concepção do conceito político de federalismo adotado pela Constituição Federal de 1988, emerge-se um empoderamento dos governos locais. In: BARACHO, José Alfredo de Oliveira. O princípio de subsidiariedade. Conceito e evolução. Rio de Janeiro: Forense, 1996, p. 21-22.
} 
recíproco, facilitando o diagnóstico dos problemas sociais e a participação motivada e responsável dos grupos sociais na solução dos problemas, gerando confiança e credibilidade". O espaço local é importante para que ocorra essa interlocução entre os cidadãos e o poder público, visto as questões de identidade, pertencimento e peculiaridades.

Nesta senda, o espaço local "pode ser entendido como parte de um processo de reconstrução da esfera pública, orientado para a democratização da gestão de políticas públicas no país, o qual tem na descentralização um de seus componentes centrais" (FARAH, 2001, p. 132). Devido à proximidade que essa esfera possui com o cidadão, o espaço público e a cidadania podem vir a se reconstruir, caso ocorra uma maior interlocução entre cidadãos e Estado diante os assuntos públicos.

No espaço local há maior possibilidade de representação dos cidadãos, pois neste espaço se instaura um sentimento de pertencimento, visto às peculiaridades e identidades culturais. Além disso, neste espaço pode se desenvolver melhor as relações pautadas na solidariedade (HERMANY, 2007, p. 264-266). Em uma perspectiva horizontal, faz-se necessário avaliar os limites e possibilidades de apropriação do espaço público pela sociedade, a partir de um municipalismo alicerçado na democracia administrativa (HERMANY, 2012, p. 122).

Além de se sentirem representados, é imprescindível que o cidadão venha a participar e deliberar em certos assuntos públicos. Conforme Vieira (2001, p. 79), "o Estado e/ou mercado não podem mais se arrogar o monopólio de planejar e praticar ações sociopolíticas de interesse público deixando de fora a sociedade". Devido ao processo de globalização e à autonomia decisória mais restrita dos Estados-nação, as associações e movimentos sociais têm ganhado força.

Diante disso, observa-se que o cidadão possui maior relação com o espaço local, por haver uma maior facilidade de diálogo com essa esfera. Neste sentido, tem-se para Joachim Krell (2003, p. 90) que "[...] o governo municipal vive mais intensamente os problemas da sociedade, possui conhecimento detalhado dos mesmos e sofre pressão mais direta da sociedade local".

Acerca da participação dos cidadãos na esfera local, tem-se que "[...] na democracia participativa esse processo é substituído por uma constante e regular participação, o que se potencializa a partir de uma dimensão local, na qual se pode construir um efetivo processo de formação democrática e legítima das decisões públicas, sejam administrativas ou legislativas" (HERMANY, 2007, p. 183). 
O mesmo pode se aferir do processo democrático deliberativo, onde se há um efetivo processo de formação democrática e legítima de decisões públicas. Dessa forma, tanto os mecanismos de participação como o de deliberação são fundamentais para este diálogo entre Estado e sociedade, se potencializando no espaço local.

A esfera local pode para muitos ser tido como um espaço simples, visto que abrange uma determinada localidade, mas é eficaz na manifestação de interesses e necessidades dos cidadãos (HERMANY, 2007, p. 184). Além do que, a partir desse lócus pode haver maior controle social, participação pública, e, evidentemente, processos democráticos deliberativos.

O espaço local possui as condições ideais para assegurar ao cidadão a plenitude do exercício de sua cidadania. Não que isso não seja possível nas demais esferas da federação, entretanto, em razão da já mencionada proximidade e pertencimento que o cidadão possui com o espaço local, se instaura uma melhor conjuntura de garantir a participação da sociedade (COSTA; REIS, 2010, p. 109).

Hermany (2007, p. 281) aponta que "[...] é a democracia local que favorece o desenvolvimento de uma cultura participativa de caráter permanente, constituindo-se num novo espaço político. Tal perspectiva desloca a discussão acerca da estrutura de desenvolvimento econômico para o espaço local, valorizando o debate realizado com os cidadãos e estimulando, com isso, a participação popular".

Neste sentido, a democracia local é fundamental, além de favorecer que as práticas de democracia participativa e deliberativa ali tenham um melhor espaço para o seu desenvolvimento. Dowbor (1998, p. 286), para isso, aponta para a necessidade de reformulação da administração pública, de modo que sejam criados mecanismos de participação simplificados e que contemplem os atores-chaves do município, que envolva todos os atores sociais.

O espaço público local se mostra, então, como o ambiente ideal para que ocorra a interação social e processos democráticos participativos e deliberativos, visto que na esfera local os cidadãos possuem maior contato com o poder público. Essa aproximação entre os cidadãos e o espaço local pode transformar essa interlocução de harmonia e de cooperação, basta que haja instrumentos disponíveis para a participação e que a mesma seja fomentada pelo Estado. 


\section{A GESTÃO DEMOCRÁTICA LOCAL E O ESTATUTO DA CIDADE}

A gestão democrática e o destaque dos municípios como importantes lócus para fomentar a ampliação de participação e deliberação dos cidadãos está inclusive explicitado no Estatuto da Cidade (Lei no 10.257/2001), tida como referência legal em termos de democracia local.

Borja e Castells (1996, p. 156) destacam 3 fatores relevantes para o processo de transformação urbana, quais sejam: (i) a sensação de crise diante a globalização econômica; (ii) a negociação entre os atores sociais e a geração de liderança local; e (iii) a vontade conjunta para que a cidade ocupe um papel de maior destaque, economicamente, socialmente e culturalmente.

Neste sentido, impende analisar alguns dispositivos da legislação supracitada, que busca a transformação urbana e a gestão democrática local. $\mathrm{O}$ artigo 2 을 do Estatuto estabelece algumas diretrizes gerais para ordenar o pleno desenvolvimento das funções sociais da cidade e da propriedade urbana, e, dentre elas, o inciso II dispõe que deverá haver "gestão democrática por meio da participação da população e de associações representativas dos vários segmentos da comunidade na formulação, execução e acompanhamento de planos, programas e projetos de desenvolvimento urbano" (BRASIL, 2001).

Além disso, a legislação, no capítulo II, estabelece diversos instrumentos da política urbana, em um rol não exaustivo, e no parágrafo 30 inclui que "os instrumentos previstos neste artigo que demandam dispêndio de recursos por parte do Poder Público municipal devem ser objeto de controle social, garantida a participação de comunidades, movimentos e entidades da sociedade civil" (BRASIL, 2001).

Acerca da elaboração e fiscalização da implementação do plano diretor o Estatuto da Cidade também ressalta que deverá ser garantida a participação da população e de associações representativas de segmentos da comunidade (BRASIL, 2001).

Ademais, o Estatuto da Cidade também dispõe um rol (não taxativo) de instrumentos a fim de garantir a gestão democrática da cidade, como órgãos colegiados de política urbana, debates, audiências e consultas públicas, dentre outros (BRASIL, 2001). No entanto, a legislação centrou-se em instrumentos participativos - embora esteja explicitado que o rol de instrumentos é exemplificativo.

A preocupação com a transformação urbana e o papel que a cidade desempenha reside em defrontar-se com determinadas questões. Primeiramente, a necessidade de dar 
respostas integradas e não setoriais às demandas da sociedade, como transporte, saúde, educação, dentre outros. Também, que se estabeleçam compromissos a partir do crescimento econômico e meio-ambiente. E, por fim, a configuração de novos espaços e mecanismos que estimulem a participação dos cidadãos, que aproximem os administrados da Administração Pública (CASTELLS; BORJA, 1996, p. 157).

Os espaços públicos, ainda, podem ser uma resposta eficaz aos desafios no âmbito urbanístico, sociocultural e político. O desafio urbanístico requer respostas sobre o ordenamento dos elementos construídos e uma dialética entre centralidades e mobilidade acessíveis a toda população. O desafio sociocultural demanda conceder qualidade ao espaço público, onde o espaço público deve cumprir uma função integradora complexa, em um processo dialético. E o desafio político se exprime na capacidade do espaço público para facilitar o acesso de todos a participação e mobilização política (BORJA; MUXí, 2003, p. 65-66).

Dessa forma, desvela-se a importância do Estatuto da Cidade para a transformação urbana. No entanto, deve-se ressaltar que a existência dessa legislação nacional de política urbana não tornou tais políticas homogêneas no Brasil. Há uma discrepância na aplicação do Estatuto nos municípios de acordo com a sociedade civil e com a sociedade política (AVRITZER, 2010, p. 214).

Avritzer (2010, p. 220) destaca que "é a força reguladora da legislação, aliada à exigência da participação, que permite controlar interesses privados que na maior parte do século XX brasileiro prevaleceram sem nenhum controle, tanto por parte da sociedade civil quanto do Estado". Nesta senda, é primordial que haja a participação dos cidadãos, para dar maior ênfase ao que disciplina o Estatuto da Cidade.

Demonstra-se, nesse sentido, a essencialidade do espaço local para propulsionar a transformação urbana e assegurar essa gestão democrática, a partir de instrumentos que aproximem os cidadãos do poder público. Cabe verificar se os mecanismos existentes promovem essa interlocução entre Administração Pública e sociedade.

\section{A DELIBERAÇÃO PÚBLICA NA ESFERA LOCAL: UM ESTUDO DOS INSTRUMENTOS}

Exposta a importância da esfera local na interlocução entre Estado e sociedade, serão tratados os instrumentos existentes para possibilitar que haja a deliberação pública, a partir desse lócus que fora trabalhado anteriormente. No entanto, não será possível auferir aqui se os 
instrumentos seguem fielmente o modelo deliberativo proposto por Jürgen Habermas ${ }^{7}$, ou seja, se cumprem os procedimentos deste processo democrático, visto que o autor estabelece diversos requisitos a serem considerados na deliberação pública.

Em suma, destaca-se que no Brasil há o orçamento participativo, que foi implementado na gestão do município de Porto Alegre, bem como os conselhos municipais, com ênfase para os conselhos de criança e adolescente, educação e saúde. Há quem entenda, ainda, que as audiências públicas se consubstanciam em instrumento deliberativo. ${ }^{8}$ No entanto, adota-se no presente trabalho a audiência pública como um instrumento participativo, visto que não ocorre a vinculação do que foi deliberado.

O plano diretor da cidade de Porto Alegre, em seu primeiro dispositivo, expressa que há a necessidade de uma gestão democrática, descentralizada e participativa. No entanto, o orçamento participativo surgiu, além desses elementos institucionais, em face da pressão de associações comunitárias (AVRITZER, 2002a).

Atualmente este orçamento participativo está estruturado em 17 assembleias regionais e 6 temáticas. Nas assembleias, os cidadãos podem tomar decisões de maneira direta, ainda que a sua participação seja mediada por algum tipo de organização (como um comitê de bairro, por exemplo). No caso das assembleias regionais, o critério de participação é o local de moradia, enquanto que na temática é o interesse (AVRITZER, 2002b).

Em estudo interessante realizado por Horochovski e Clemente (2012, p. 137), os mesmos observaram como se dava os níveis de participação nos orçamentos participativos (OP) de Porto Alegre, Belo Horizonte, Recife e Curitiba. Quanto a este instrumento, avaliado na capital gaúcha, tem-se que: "o OP é um espaço aberto à participação dos cidadãos de Porto Alegre, desde que eles organizem-se em alguma forma de ação coletiva - o que já introduz um limite à participação mais ampla quando se considera a baixa taxa de adesão a organizações associativas".

\footnotetext{
7 No presente ensaio não é possível analisar todos os requisitos da teoria democrática deliberativa habermasiana. Entretanto, os esforços serão no sentido de verificar se alguns dos elementos principais dos mecanismos deliberativos estão em consonância e se estes demonstram-se suficientes para a inclusão dos cidadãos nas deliberações públicas.

8 Nesta perspectiva, há um trabalho de dissertação que trabalha a audiência pública como um instrumento indutor deste modelo de processo democrático deliberativo que se trabalhou no primeiro ponto deste artigo. Para mais, ver: SILVEIRA, Flavio Pavlov da. A audiência pública como um instrumento indutor do modelo de democracia deliberativo-procedimental de Jürgen Habermas. 2010. $163 \mathrm{f}$. Dissertação (Mestrado) - Universidade Regional Integrada do Alto Uruguai e das Missões - URI, Santo Ângelo, 2010.
} 
Dessa forma, se o cidadão não possui nenhum engajamento em organizações associativas, o mesmo tem a sua participação restrita no processo democrático deliberativo (pelo menos tomando-se como exemplo o município de Porto Alegre).

Outro estudo específico sobre o orçamento participativo de Porto Alegre concluiu que, a partir dos números coletados, verifica-se a pouca participação dos cidadãos, que pode estar correlacionada com o desgaste na estrutura representativa do OP (AMARAL; CARVALHO, 2018, p. 484).

O mesmo possui um quadro diferente no município de Recife, onde é facultado a todos a participação nas instâncias decisórias das primeiras fases do ciclo, onde os cidadãos são agrupados em pequenos grupos a fim de que discutam acerca dos investimentos (HOROCHOVSKI; CLEMENTE, 2012, p. 137).

Quando avaliada a variante da deliberação, os resultados encontrados na pesquisa foram que a sua presença é fraca nos municípios que dispõem de orçamento participativo. Um dos motivos elencados é que o orçamento do qual se delibera não é expressivo, e, ainda, pois as prefeituras ainda desempenham um papel determinante na destinação dos recursos (HOROCHOVSKI; CLEMENTE, 2012, p. 141).

Este último elemento possui relação com o fato de que o poder público, normalmente detentor do poder, ainda tem certa relutância em cedê-lo, de modo que os cidadãos o exerçam. Entretanto, visto que os cidadãos são os maiores interessados nos assuntos públicos, essa situação deve ser modificada.

Os resultados colhidos dos instrumentos deliberativos existentes vão ao encontro com o que Roberto Gargarella (2015) pontua, quando realiza um estudo das constituições latinoamericanas nos dois últimos séculos. O constitucionalismo evoluiu muito na inclusão de direitos, mas as estruturas de poder, chamadas pelo autor de "sala de máquinas da constituição" permaneceram sem grandes transformações.

"Agindo dessa maneira, reformistas legais mantêm fechadas as portas da "sala de máquinas" da Constituição: o núcleo da maquinaria democrática não é modificado. A máquina da Constituição não se transforma no objeto de atenção principal dos reformadores" (GARGARELLA; PÁDUA; GUEDES, 2016, p. 38). Neste viés, percebe-se que há instrumentos para a participação e deliberação nos assuntos públicos, mas há entraves existentes, visto que a sala de máquinas está fechada. Isso implica que a efetividade desses mecanismos depende de modificações na organização do poder. 
As estruturas do poder, da forma em que estão postas, não permitem o real acesso dos cidadãos na sala de máquinas. Isto porque "[...] a velha organização política hiperpresidencialista tende a bloquear todas as iniciativas direcionadas a colocar em movimento as iniciativas de empoderamento popular incluídas nas novas Constituições" (GARGARELLA; PÁDUA; GUEDES, 2016, p. 38).

Quanto aos conselhos municipais, os mesmos se consubstanciam em meios de deliberação que abarcam a tomada de decisões sobre políticas locais, bem como a regulação dos atos do governo. Avritzer (1996, p. 42-43) traz que uma peculiaridade dos orçamentos participativos e dos conselhos municipais se dá na questão de que esses arranjos deliberativos se consubstanciam em formas ampliadas de participação.

O que o autor coloca acima é essencialmente o que ocorre (ou deveria ocorrer) em um processo democrático deliberativo: há participação dos envolvidos, além de haver a argumentação nas discussões sobre os melhores investimentos a serem feitos para o interesse público.

Não é possível trazer um panorama geral dos conselhos municipais, visto que os mesmos variam de uma área para outra (educação, saúde, etc) e de município para outro. No entanto, a dimensão formal dos conselhos municipais possui natureza deliberativa e fomento à participação política.

Contudo, traz-se aqui um exemplo do conselho municipal de saúde de um município do Rio Grande do Sul, onde um estudo realizou uma análise desse conselho à luz da matriz teórica deliberativa habermasiana. Em um primeiro momento do estudo de caso, o autor arguiu os 16 conselheiros, e, dentre os resultados colhidos, ressalta-se a unanimidade quanto à impressão ${ }^{9}$ por parte dos conselheiros de que as reuniões e deliberações são públicas e abertas aos cidadãos e também de forma unânime de que há abertura e possibilidade dos cidadãos levarem demandas aos integrantes do Conselho (ALVES, 2017, p. 93-95).

Os conselheiros foram indagados da forma em que ocorre o recebimento de demandas dos cidadãos. Com isso, verificou-se que não há uma sistematização interna, podendo ser de diversas maneiras, variando de ofícios a pedido de palavra no plenário, ou serem levadas diretamente a algum conselheiro. Ainda, 15 dos 16 conselheiros responderam que há uma liberdade sobre a escolha dos temas e proposições de pautas a serem tratadas nas reuniões (ALVES, 2017, p. 95-98).

\footnotetext{
${ }^{9} \mathrm{O}$ termo impressão, empregado e justificado pelo autor que desenvolveu o estudo de caso é no sentido da subjetividade da resposta, pois esta se decorre a partir da experiência e da perspectiva do conselheiro.
} 
Acerca da fiscalização, em caso de denúncias, o estudo constatou que o conselho "[...] possui um modo de operação deliberativo, pois, embora os conselheiros tenham o poder de realizar a fiscalização de forma individual, preferem, utilizando da própria estrutura do Conselho, realizar a fiscalização e o controle por meio das comissões, que são criadas para essa finalidade pelo próprio órgão" (ALVES, 2017, p. 111).

Um ponto interessante evidenciado na análise do conselho municipal de saúde, a partir de entrevista com o presidente do Conselho, foi que a participação da sociedade junto ao conselho se dá pelos representantes das entidades de classe que compõem o conselho, não os cidadãos participando diretamente das sessões (ALVES, 2017, p. 121). Revela-se aqui uma semelhança com o que foi detectado nos estudos dos orçamentos participativos, em que pouco se verifica uma participação individual nas deliberações, mas fundamentalmente através de associações e entidades.

Acerca da pouca expressiva participação da sociedade nas deliberações do conselho municipal de saúde, tem-se que é pela desinformação e desconhecimento dos cidadãos acerca da atuação do conselho (ALVES, 2017, p. 121-122). Ademais, como visto acima, os cidadãos também se sentem representados pelas entidades de classe. Cabe aqui mencionar que o conselho é composto por 50\% de representantes da sociedade, e que "os representantes dos usuários são os que têm posição mais firme no Conselho, e que tal forma de atuação se dá pelo fato de defenderem o sistema como um todo e não determinado interesse ou ramo de atividade, o que de fato faz concluir pela importância da participação da sociedade nas deliberações do Conselho Municipal de Saúde" (ALVES, 2017, p. 141-142).

Contudo, ressalta-se que a abordagem desse estudo de caso acerca das deliberações no conselho municipal de saúde foi em grande parte construída a partir das perspectivas e experiências dos conselheiros. Nesse sentido, não se tem aqui uma perspectiva dos cidadãos com relação à atuação e deliberações realizadas no conselho, muito em razão do próprio desconhecimento dos cidadãos. Esse é um dos maiores problemas que se percebe, a falta de informação como um entrave à participação cidadã.

Após uma breve análise do Conselho Municipal de Saúde em município do Estado do Rio Grande do Sul, passa-se para a abordagem de um estudo acerca do Conselho Municipal de Meio Ambiente em determinado município do Estado do Rio de Janeiro, que avalia a qualidade da participação e representação da sociedade nas deliberações.

A estrutura do Conselho Municipal de Meio Ambiente é composta por 28 instituições, comportando 14 representantes de organizações governamentais e 14 representantes de 
organizações não governamentais. Os autores do estudo, em um primeiro momento, analisaram o potencial de cooptação ${ }^{10}$ dos conselheiros, concluindo que o conselho possui 5 com alto potencial de cooptação, 8 com médio potencial de cooptação e 8 com baixo potencial de cooptação. Dessa forma, as estatísticas apontam que apenas 38\% apresentam baixo nível de cooptação (LIRA; MACIEL, 2013, p. 79-80).

Outra constatação foi que no ano de 2010, por exemplo, de doze reuniões previstas apenas seis obtiveram o quórum necessário para a sua realização, tendo sido as demais canceladas pela falta dos representantes. Além disso, outros problemas são apontados, como as pautas das reuniões, por não possuírem assuntos mais objetivos e relevantes para a sociedade. Ademais, o teor técnico das reuniões se torna um empecilho para uma maior participação, pois muitas vezes foge ao conhecimento dos conselheiros (LIRA; MACIEL, 2013, p. 80-81).

Neste sentido, nota-se a discrepância de conselhos municipais de acordo com a área e município - aqui acredita-se que a variável principal seja mesmo a área de atuação, pois os conselhos municipais de saúde costumam ter as deliberações vinculativas e uma força de operação ampliada -, sendo que esse conselho municipal de meio ambiente apresentou diversas dificuldades democráticas locais.

Dessa forma, cabe aqui ressaltar que não é possivel se ter uma conclusão de todos os instrumentos deliberativos, visto que os mesmos diferem de um município para outro. No entanto, a partir da breve análise dos orçamentos participativos, é viável se alcançar certos resultados preliminares, demonstrando-se assim que ainda há muito para evoluir em termos de democracia deliberativa no espaço local. Já acerca dos conselhos municipais, demonstra-se que a inclusão dos cidadãos nas deliberações difere de acordo com a área do conselho e também pode apresentar variações pela forma em que se estrutura em cada município.

\footnotetext{
${ }^{10}$ A cooptação é um sistema de organização pela qual uma associação qualquer de pessoas nomeia internamente os seus próprios membros. O potencial de cooptação é avaliado a partir de nível baixo, médio e alto, analisando o perfil do conselheiro. O potencial de cooptação alto seria um perfil de conselheiro que seja funcionário da prefeitura não concursado ou representante de instituições com alinhamento político com a prefeitura. O potencial de cooptação médio seria funcionário da prefeitura concursado ou representante de instituições que desenvolvem projetos financiados pela prefeitura. E um potencial de cooptação baixo seria representante de instituições privadas e públicas não dependentes da prefeitura. In: LIRA, Rodrigo Anido; MACIEL, Fabrício Barbosa. Representação, participação e cooptação no Conselho Municipal de Meio Ambiente em Campos dos Goytacazes/RJ. Revista Brasileira de Planejamento e Desenvolvimento, v. 2, n. 1, p. 72-85, jan./jun., 2013, p. 79.
} 


\section{CONSIDERAÇÕES FINAIS}

Observou-se no presente trabalho que as matrizes teóricas da democracia deliberativa, sob o referencial teórico de Habermas, enfatizam a ampla participação e a argumentação. A teoria do discurso (mais conhecida como teoria da ação comunicativa), é o procedimento desenvolvido pelo qual, através dele, se dá a tomada de decisões.

A partir de um breve estudo do processo democrático deliberativo, destacou-se que o espaço local é o lócus ideal para que ocorra essa interlocução entre os cidadãos e o poder público. Isto pois, normalmente as necessidades dos indivíduos se resolvem facilmente a partir da esfera local em que estão inseridos. Ademais, o cidadão possui maior proximidade com o espaço local, em virtude de uma questão de pertencimento.

Diante disso, se observou que deve ser incentivada maior participação e canais para a deliberação em assuntos públicos no espaço local, e isso ainda resultaria em uma reconstrução da cidadania, que se tornaria mais fortalecida com essas práticas.

Desse modo, efetuou-se uma análise dos instrumentos de exercício da deliberação estão disponíveis no Brasil, que são, em suma, o orçamento participativo e os conselhos municipais. Demonstrou-se que esses mecanismos podem ser significativos para a ampliação da participação, desde que se realize certas alterações.

A primeira - e a mais importante delas - é que o poder público aceite que os cidadãos, maiores interessados nos assuntos públicos, devem ser atores sociais, participando de deliberações quando for possível. Ainda, que se abra maior espaço para a participação dos cidadãos, que em certos casos devem fazer parte de associações para poder deliberar (como é o caso do orçamento participativo de Porto Alegre).

Neste sentido, conclui-se que poderia haver mais espaços de participação e deliberação em municípios. Há municípios menores, que devido à falta de orçamento ou devido à estrutura de poder clientelista, não dispõe de instrumento participativo. É imprescindível que haja esses espaços para os cidadãos, até para que a cidadania seja ressignificada.

Importante conclusão, ainda, se faz no sentido de que os instrumentos existentes somente terão o significado proposto pela teoria democrática habermasiana quando houver uma reestruturação nas salas de máquinas da Constituição. Isto porque a estrutura de poder, nos moldes em que está delineada, não permite a inclusão e o empoderamento popular, e os mecanismos deliberativos implicam que haja o protagonismo dos cidadãos. 


\section{REFERÊNCIAS}

ALVES, Cássio Guilherme. Controle social de políticas públicas: os conselhos municipais e sua forma de atuação e controle na execução de políticas públicas - uma observação crítica sobre a atuação do Conselho Municipal de Saúde de Santa Cruz do Sul. 2017. 151 f. Dissertação (Mestrado) - Universidade de Santa Cruz do Sul (UNISC), Santa Cruz do Sul, 2017.

AMARAL, Claudia Tannus Gurgel do; CARVALHO, Francisco Toniolo de. Democracia e deliberação: a escolha popular das políticas públicas locais - o caso do orçamento participativo de Porto Alegre (OPPOA). Revista de Direito da Cidade, Rio de Janeiro, vol. 10, n. 1, p. 463-485, 2018.

AVRITZER, Leonardo. A moralidade da democracia: ensaios em teoria habermasiana e teoria democrática. São Paulo: Perspectiva; Belo Horizonte: UFMG, 1996.

Modelos de deliberação democrática: uma análise dos orçamentos participativos no Brasil. In: SANTOS, Boaventura de Souza (Org.). Democratizar a democracia: os caminhos da democracia participativa. Rio de Janeiro: Civilização Brasileira, 2002a.

O Estatuto da Cidade e a democratização das políticas urbanas no Brasil. Revista Crítica de Ciências Sociais, Coimbra, n. 91, p. 205-221, 2010.

O orçamento participativo: as experiências de Porto Alegre e Belo Horizonte. In: DAGNINO, Evelina. (Org.). Sociedade civil e espaços públicos no Brasil. São Paulo: Paz e Terra, 2002b.

BARACHO, José Alfredo de Oliveira. O princípio de subsidiariedade. Conceito e evolução. Rio de Janeiro: Forense, 1996.

BORJA, Jordi; MUXÍ, Zaida. El espacio público, ciudad y ciudadanía. Barcelona: Electa, 2003.

CASTELLS, Manuel; BORJA, Jordi. As cidades como atores políticos. Revista Novos Estudos CEBRAP, São Paulo, n. 45, p. 152-166, 1996. 
COHEN, Joshua. Deliberation and Democratic Legitimacy, p. 342-360. In: MATRAVERS, Derek; PIKE, Jon (Eds.). Debates in contemporary political philosophy: an anthology. Estados Unidos da América e Canadá: Routledge, 2003.

COSTA, Marli Marlene Moraes da; REIS, Suzéte da Silva. Espaço local: o espaço do cidadão e da cidadania, p. 103-123. In: HERMANY, Ricardo (Org.). Gestão local e políticas públicas. Santa Cruz do Sul: IPR, 2010.

CUNNINGHAM, Frank. Teorias da democracia: uma introdução crítica. Porto Alegre: Artmed, 2009.

DOWBOR, Ladislau. A reprodução social: propostas para uma gestão descentralizada. Petrópolis: Vozes, 1998.

Democracia econômica: alternativas de gestão social. Petrópolis: Vozes, 2008a.

O que é poder local? São Paulo: Brasiliense, 2008b.

FARAH, Marta Ferreira Santos. Parcerias, novos arranjos institucionais e políticas públicas no nível local de governo. Revista de Administração Pública, Rio de Janeiro, v. 35, n. 1, p. 119-145, 2001.

GARGARELLA, Roberto; PÁDUA, Thiago; GUEDES, Jefferson. Constitucionalismo latinoamericano: direitos sociais e a "sala de máquinas" da Constituição. Revista Universitas Jus, Brasília, v. 27, n. 2, p. 33-41, 2016

GARGARELLA, Roberto. La sala de máquinas de la Constitución. Dos siglos de constitucionalismo en América Latina (1810-2010). Buenos Aires: Katz, 2015.

HABERMAS, Jürgen. A inclusão do outro. 3. ed. São Paulo: Loyola, 2007.

Aclaraciones a la ética del discurso, 2000. Disponível em: <http://www. inau.gub.uy/biblioteca/seminario/eticadiscurso.pdf>. Acesso em: 21 ago. 2016.

Direito e Democracia: entre facticidade e validade. Vol. I e II. Rio de Janeiro: Tempo Brasileiro, 2003. 
Reconciliación mediante el uso público de la razón. In: HABERMAS, Jürgen; RAWLS, John. Debate sobre el liberalismo político. Barcelona: Ariel, 1998.

HERMANY, Ricardo. Município na Constituição: poder local no constitucionalismo lusobrasileiro. Curitiba: Juruá, 2012.

(Re)Discutindo o espaço local: uma abordagem a partir do direito social de Gurvitch. Santa Cruz do Sul: Edunisc, 2007.

HOROCHOVSKI, Rodrigo Rossi; CLEMENTE, Augusto Junior. Democracia deliberativa e orçamento público: experiências de participação em Porto Alegre, Belo Horizonte, Recife e Curitiba. Revista de Sociologia e Política, São Paulo, v. 20, n. 43, p. 127-157, 2012.

KRELL, Joachim Andreas. O Município no Brasil e na Alemanha: Direito e Administração Pública comparados. São Paulo: Oficina Municipal, 2003.

LEAL, Rogério Gesta. Demarcações conceituais preliminares da democracia deliberativa: matrizes habermasianas. In: LEAL, Rogério Gesta. A democracia deliberativa como nova matriz de gestão pública: alguns estudos de casos. Santa Cruz do Sul: EDUNISC, 2011.

LIRA, Rodrigo Anido; MACIEL, Fabrício Barbosa. Representação, participação e cooptação no Conselho Municipal de Meio Ambiente em Campos dos Goytacazes/RJ. Revista Brasileira de Planejamento e Desenvolvimento, Paraná, v. 2 , n. 1 , p. $72-85$, jan./jun., 2013.

MAGALHÃES, José Luiz Quadros de. Pacto Federativo. Belo Horizonte: Mandamentos, 2000.

MONTEIRO, Geraldo Tadeu. Democracia Deliberativa. In: BARRETO, Vicente de Paulo (Coord.). Dicionário de Filosofia do Direito. Rio de Janeiro: Renovar, São Leopoldo: Unisinos, 2006, p. 195199.

MOREIRA, Luiz. Fundamentação em Habermas. Belo Horizonte: Mandamentos, 2002. 
OLIVEIRA, António Cândido de. A autonomia local na Europa: um pilar da democracia. In: Confederação Nacional de Municípios. O poder local na construção de uma nova realidade. Brasília: CNM, 2012, p. 68-102.

OLIVEIRA, Manfredo Araújo. Reviravolta lingüístico-pragmática na filosofia contemporânea. São Paulo: Loyola, 1996.

RAWLS, John. Uma teoria da justiça. São Paulo: Martins Fontes, 1997.

SILVEIRA, Flavio Pavlov da. A audiência pública como um instrumento indutor do modelo de democracia deliberativo-procedimental de Jürgen Habermas. 2010. 163 f. Dissertação (Mestrado) - Universidade Regional Integrada do Alto Uruguai e das Missões - URI, Santo Ângelo, 2010.

VIEIRA, Listz. Os Argonautas da Cidadania: a sociedade civil na globalização. Rio de Janeiro: Record, 2001.

Trabalho enviado em 06 de abril de 2018

Aceito em 25 de abril de 2018 